\title{
Incidence of retromolar canal in Egyptian population using CBCT: a retrospective study
}

\author{
Mahmoud Sayed Mahmoud Badry ${ }^{1 *}$, Fatma Mostafa El-Badawy² and Walaa Mohamed Hamed²
}

\begin{abstract}
Background: Many studies have been done to investigate the incidence and the course of the retromolar canal (RMC) in different populations either osseous studies using cadavers or dry mandibles, panoramic studies, or cone beam computed tomography (CBCT) studies. The location of the RMC is in the retromolar area distal to the third mandibular molar. The retromolar area is considered an imperative site where many dental surgeries are being held.

The aim of this study is to determine the incidence of RMC in the Egyptian population using CBCT and measure the distance between the RMF and neighboring anatomical landmarks to better allocate the RMC and RMF and avoid the complications.

Two hundred and fourteen CBCT scans were examined to detect the presence of RMC. Their course was classified to 3 main types $A, B$, and $C$, and linear measurements were done from the retromolar foramen (RMF) to the 2nd and 3rd molars in anteroposterior direction and from the RMF to the mandibular foramen (MF) in anteroposterior and mediolateral directions.

Results: The RMC was present in 24 scans from the 214 with $11.2 \%$ incidence rate. The most common type was found to be type A, and type C was the rarest. The RMC has no significant difference between males and females, unilateral and bilateral distribution, and right and left sides. The linear measurements from the RMF to the 2nd and 3rd molars are $14.70 \pm 5.07 \mathrm{~mm}$ and $4.26 \pm 4.21 \mathrm{~mm}$, respectively, and from the RMF to the MF in anteroposterior and mediolateral directions are $15.69 \pm 3.43 \mathrm{~mm}$ and $2.62 \pm 1.60 \mathrm{~mm}$, respectively.

Conclusions: The incidence rate of RMC in Egyptian population represents $11.2 \%$. The use of CBCT is quite important in the evaluation of the retromolar area to visualize the presence of the RMC or RMF and avoid the complications occurring due to different dental surgical procedures performed in the aforementioned site.
\end{abstract}

Keywords: Retromolar foramen, Retromolar canal, CBCT, Egyptian population

\section{Background}

Recent imaging modalities have brought attention to anatomical variations of the mandible, such as bifid mandibular canals [1], accessory mental foramina [2, 3], lingual foramina [4], and RMF [5]. The nerve of retromolar canal (RMC) is an anatomical variation of the mandible in the retromolar area which was thought to

\footnotetext{
* Correspondence: mahmoud@dentascan.net

${ }^{1}$ The British University in Egypt, Cairo, Egypt

Full list of author information is available at the end of the article
}

arise from the accessory inferior alveolar nerve (IAN) $[6-8]$ or the long buccal nerve $[9,10]$.

A neurovascular bundle that runs through the RMC contains veins, arteries, and myelinated nerve fibers [11, 12]. The course of RMC has been studied in many populations and races, and it varies from one individual to the other and was found to exhibit either a vertical or a horizontal course. It may also appear as an independent canal that starts from a separate foramen in mandibular ramus and ends in the retromolar fossa with the opening 
of RMF. In other instances, its course may start from the retromolar fossa and end in the radicular portion of the lower third molar with no evident relation with the IAN.

What makes the RMC of utmost importance is its location in the retromolar area distal to the third mandibular molar. The retromolar area is considered an imperative site where many surgeries are being held, for instance the removals of impacted lower wisdoms, sagittal split osteotomy, harvesting bone, and implant placement. Thus, the lack of knowledge of this variation during different dental procedures can lead to adverse effects such as difficulty in achieving profound local anesthesia of mandibular molar area due to accessory innervation from the retromolar nerve, traumatic neuroma, severe bleeding, or facial paresthesia "sensory deficits" [13, 14].

The course of the RMC has been investigated in many studies based on population and race. Starkie and Stewart found that it could exhibit either a vertical or a horizontal course [6]. von Arx et al. and Ossenberg. found that it may appear as an independent canal that starts from a separate foramen in mandibular ramus and ends in the retromolar fossa with the opening $\operatorname{RMF}[11,14]$. However, Patil et al. reported that the course starts from the retromolar fossa and ends in the radicular portion of the lower third molar with no evident relation with the IAN [5]. RMC and its origin, incidence, route, and relations with the surrounding structures were quite reported in literature $[15,16]$. In addition, macroscopic osseous studies were performed by Jablonski et al. and Schejtman et al. and confirmed the relation of the retromolar nerve with the IAN or the long buccal nerve [ 9 , 17]. Thus, the retromolar canal is being of clinical interest as it may convey additional or aberrant neurovascular structures to/from the posterior mandible and the cheek.

Imaging modalities in dental fields like panorama and CBCT have significant importance in visualizing the anatomical variations. Panoramic radiograph-based studies were numerously conducted, but owing to their twodimensional (2D) nature, the diagnostic value is limited by the geometric distortions and anatomical superimpositions. The capability of the panoramic radiographs was found to be not efficient in the detection of the incidence rate, or either the relation of the RMC [14, 18]; three-dimensional (3D) modality may be required for detailed interpretation. The use of 3D imaging modalities such as multislice computed tomography (MSCT) and CBCT has a great impact on oral and maxillofacial disciplines, and its usage became quite indispensable in dental or non-dental fields [19]. However, the CBCT offers much lower radiation dose, shorter scanning time, and reduced cost and it also introduced revolutionary thirdparty software packages which helped dentists and dentomaxillofacial specialists to navigate the scans independently [20].

The revolutionary introduction of the $\mathrm{CBCT}$ in the dental field expedites the investigation of such abnormal variation regarding the incidence and the course of the RMC. The results showed much higher incidence rate, accuracy, and specificity compared to panoramic radiographs $[5,12,14,21]$.

Many studies have been done to investigate the incidence and the course of the RMC in different populations either osseous studies using cadavers or dry mandibles, panoramic studies, or CBCT studies [5, 2225]. A recent study was conducted by the Faculty of Medicine, Suez Canal University, on Egyptian dry human mandibles to find the occurrence of the RMF and found that the RMF was observed in three mandibles out of the 11 included in this study with $23 \%$ occurrence rate [26]; this study sample is not enough to represent the Egyptian population. Hence, the current study will investigate more about these variations in the Egyptian population to provide detailed information about the RMC and RMF. This data may reduce the possible complications that might be encountered in dental surgical procedures performed at this site and will emphasize the importance of prior CBCT scans to avoid the complications.

\section{Methods}

This sample size was determined following a power analysis with estimated probability 0.1 based on previous research, confidence interval 0.95 , and margin of error $5 \%$. Digital Imaging and Communications in Medicine (DICOM) files from 214 Egyptian subjects, 104 males and 110 females, representing 428 right and left sides were anonymized and selected from a pre-existing database housed at Ain Shams University, School of Dentistry, which were performed for dental impactions, implants, oral surgeries, and orthodontic treatment purposes. Male and female patient scans were selected between 2015 and 2017 with an age range between 15 and 70 years.

All cases used in this study were scanned using i-CAT next generation $\mathrm{CBCT}$ scanner (i-CAT 17-19, Imaging Sciences International LLC, Hatfield, PA, USA). All DICOM images collected were evaluated and examined using InVivoDental ${ }^{\circ}$ 5.4.5 (Anatomage, California, USA)

This study is a retrospective study conducted on 214 scans involving 428 mandibular sides observed by two dental radiologists with more than 5 years' experience.

Each case was first examined on the multi-planner reconstruction (MPR). Axial, coronal, and sagittal views were scrolled to identify the presence of RMF or RMC. Scans were examined thoroughly for the presence of any opening on the outer surface of the mandible in the 
retromolar area, which may indicate the RMF or any branching from the inferior alveolar canal. Cross sections, reconstructed panoramic view, and reconstructed slice panoramic view were also scrolled thoroughly in arch-section module to facilitate tracing of the inferior alveolar canal (IAC) and identify any sign of branching in the retromolar area from the IAC indicating the presence of RMC (Fig. 1).

When the RMF or RMC is identified, linear measurements were done and recorded for statistical analysis. Sagittal cut was adjusted to be passing through the RMF and the middle of the 2nd and the 3rd molars, and then, linear measurement was done in the anteroposterior direction (Fig. 2). Axial cut was adjusted to be passing through the RMF and the mandibular foramen, and the linear measurements was done between them in both anteroposterior and mediolateral direction (Fig. 3).

All RMCs were classified according to their course and direction to three main types according to Patil et al.'s classification [5] (Fig. 4):

A. Type A in which the RMC branches from the mandibular canal distal to the third molar and course superiorly to open in the retromolar area with RMF. Two variations from type A were noted, A1 (Fig. 4a) and A2 (Fig. 4b). In A1, the canal runs in a straight manner superiorly to open in the retromolar area; however, in A2, the canal runs in a curved manner anteriorly then postero-superiorly to open the retromolar area.

B. Type B in which the canal starts from the retromolar area by the RMF and ends in the radicular portion of the 3rd molar (Fig. 4c).

C. Type $\mathrm{C}$ in which the canal starts branching early from the mandibular canal near the mandibular foramen and ends in a higher level in the retromolar area (Fig. 4d).

\section{Statistical analysis}

Results in the current study were analyzed and tabulated using the Statistical Package for Social Science (SPSS) software as described by Freitas et al. for their statistical analysis [27]. Intra-reviewer analysis and inter-reviewer analysis were done to determine the reliability of measurements, frequencies, and percentages to find the percentage of RMF in the sample, and $X^{2}$ (chi-square test) and Fisher's exact test were calculated to identify the significant incidence.

\section{Results}

The sample consisted of 214 patient scans, 104 males and 110 females. The results showed the presence of 13 RMCs in males and 11 RMCs in females with a total of 24 patients having RMCs out of the 214 and incidence rate of $11.2 \%$ (Table 1 ).

According to the 428 right and left sides in the total sample size, the results showed the presence of 17 RMCs in males and 13 RMCs in females with a total of 30 RMCs out of 428 sides with incidence rate of $7 \%$. The prevalence of RMCs in the left side $(n=16,3.7 \%)$ was slightly higher than that of the right side $(n=14,3.3 \%)$, but with no significant difference (Table 2).

The incidence of the different types of RMCs was evaluated, and type A was found to be the most common type ( $n=23,5.37 \%)$ which has two subtypes A1 and A2. Type $\mathrm{B}$ is found to be the 2 nd most common type $(n=$ $5,0.7 \%)$. Type $\mathrm{C}$ was the rarest type $(n=2,0.23 \%)$ (Table 3).

The unilateral presence of RMCs $(n=18,8.4 \%)$ was found to be higher than the bilateral presence of RMCs $(n=6,2.8 \%)$, but also with no significant difference (Table 4).

The distance from the RMF to the second and third molars in the anteroposterior direction was calculated and found to be $14.70 \pm 5.07 \mathrm{~mm}$ and $4.26 \pm 4.21 \mathrm{~mm}$, respectively. The distance from the RMF to the mandibular foramen in both the anteroposterior direction and the mediolateral direction was calculated and found to be $15.69 \pm 3.43 \mathrm{~mm}$ and $2.62 \pm 1.60 \mathrm{~mm}$, respectively (Table 5).

\section{Discussion}

Many studies have been conducted on the incidence rate of RMC and RMF using panoramic radiograph which all have reported low incidence rate. Recently, highresolution $\mathrm{CBCT}$ has become notably effective for confirming anatomical variation of mandibular canal that cannot be assessed using panoramic radiograph which

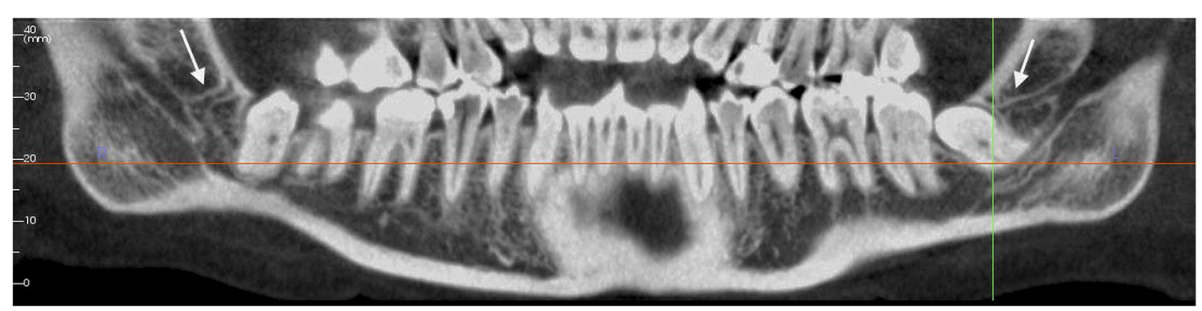

Fig. 1 Slice panoramic view. Slice view of reconstructed panoramic image, the two white arrows pointing to the RMC bilaterally 


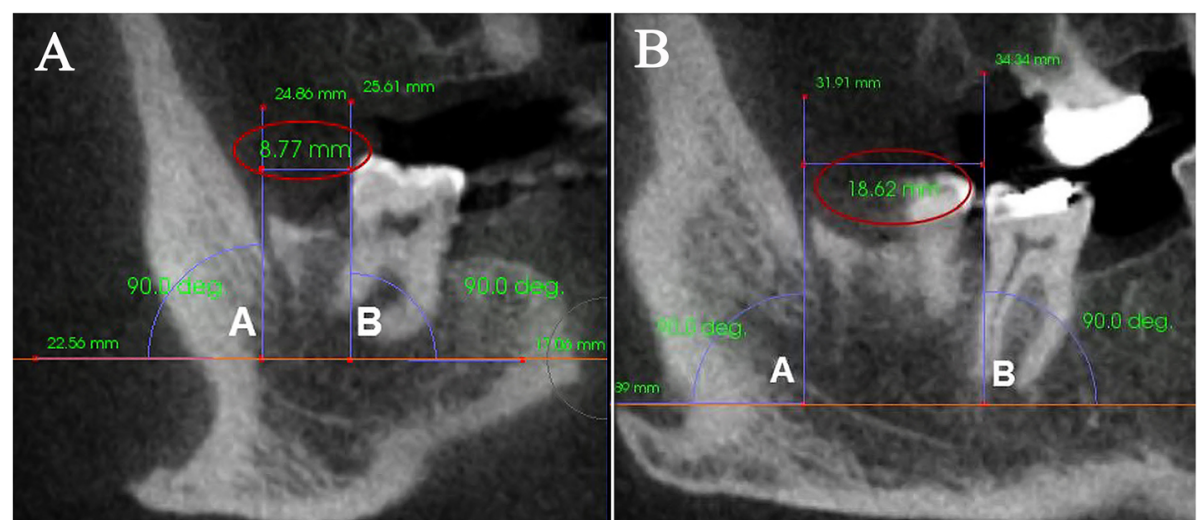

Fig. 2 Linear measurements between the RMF and the 2nd and 3rd molars in anteroposterior direction. a Sagittal cut: " $A$ " is the line from the RMF perpendicular to the axial plane reference line, " $B$ " is the line tangent to the 3rd molar distal surface and perpendicular to the axial plane reference line, and the linear measurement between the RMF and distal surface of the $3 \mathrm{rd}$ molar is $8.77 \mathrm{~mm}$. $\mathbf{b}$ Sagittal cut: " $\mathrm{A}$ " is the line from the RMF perpendicular to the axial plane reference line, "B" is the line tangent to the 2nd molar distal surface and perpendicular to the axial plane reference line, and the linear measurement between the RMF and distal surface of the 2 nd molar is $18.62 \mathrm{~mm}$

all have reported a wide incidence rate ranging from 6.1 to $72 \%[21,28]$.

Numerous studies have been conducted studying the incidence of retromolar canal in different populations, all with varying results. The studied populations included Americans, Canadians, Argentinians, Italian, Japanese, Turkish, Brazilian, and Indian. However, there has been no study conducted on the Egyptian population except for only one study that has been conducted on 11 dry mandibles [5, 22-24, 29]. Hence, the current study was aimed to identify the incidence of retromolar canal in the Egyptian population using CBCT.
The CBCT scans of $0.25 \mathrm{~mm}$ voxel size were selected which allowed us to evaluate and detect the RMC and RMF of 0.5 diameter or larger, identifying the course and the location of these canals and foramina with good precision and accuracy. Higher resolution scans of 0.125 $\mathrm{mm}$ voxel size were available from the same i-CAT next generation $\mathrm{CBCT}$ machine in our archive but were not used as they provide limited field of view (FOV) to $4 \mathrm{~cm}$ $\times 16 \mathrm{~cm}$ which will limit the height of the scan and will not be enough to evaluate the ramus and the mandibular foramen areas.

The Invivo dental software was used in our study as a reliable and accurate measuring software in accordance
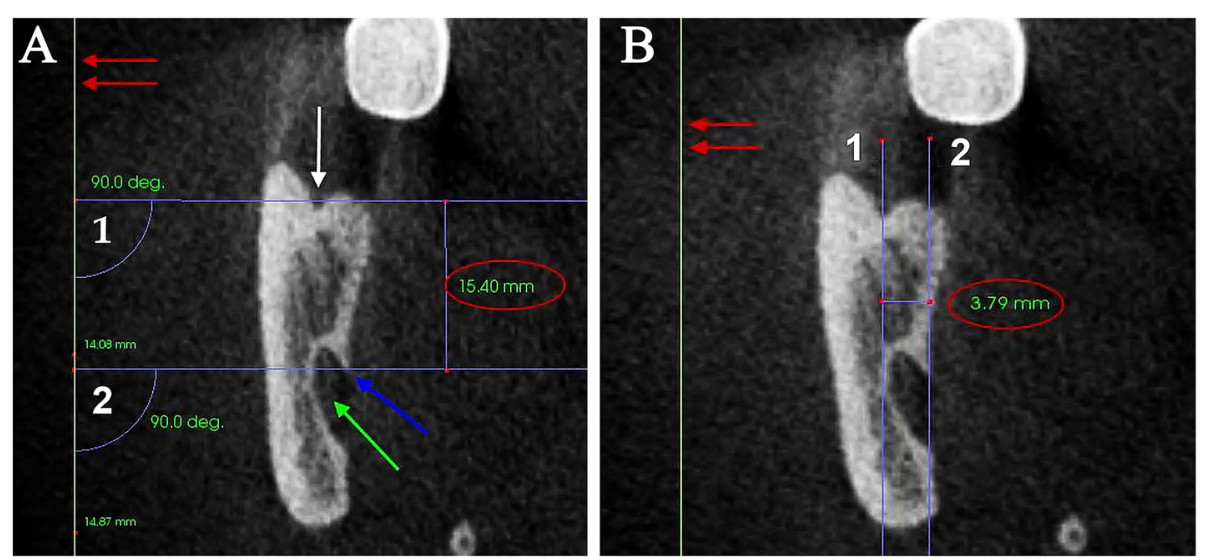

Fig. 3 Linear measurements between the MF and RMF in anteroposterior and mediolateral directions. a Axial cut showing the red arrows pointing to the sagittal plane reference line, the green arrow to the MF, and the blue arrow to the lingula. (1) Line drawn from the middle of the RMF perpendicular to the sagittal plane reference line. (2) Line drawn from the middle of the MF perpendicular to the sagittal plane reference line. The linear measurement between the RMF and MF in anteroposterior direction is $15.4 \mathrm{~mm}$. $\mathbf{b}$ Axial cut showing the red arrows pointing to the sagittal plane reference line. (1) Line drawn from the middle of the RMF parallel to the sagittal plane reference line. (2) Line drawn from the middle of the MF parallel to the sagittal plane reference line. The linear measurement between the RMF and MF in mediolateral direction is $3.79 \mathrm{~mm}$ 

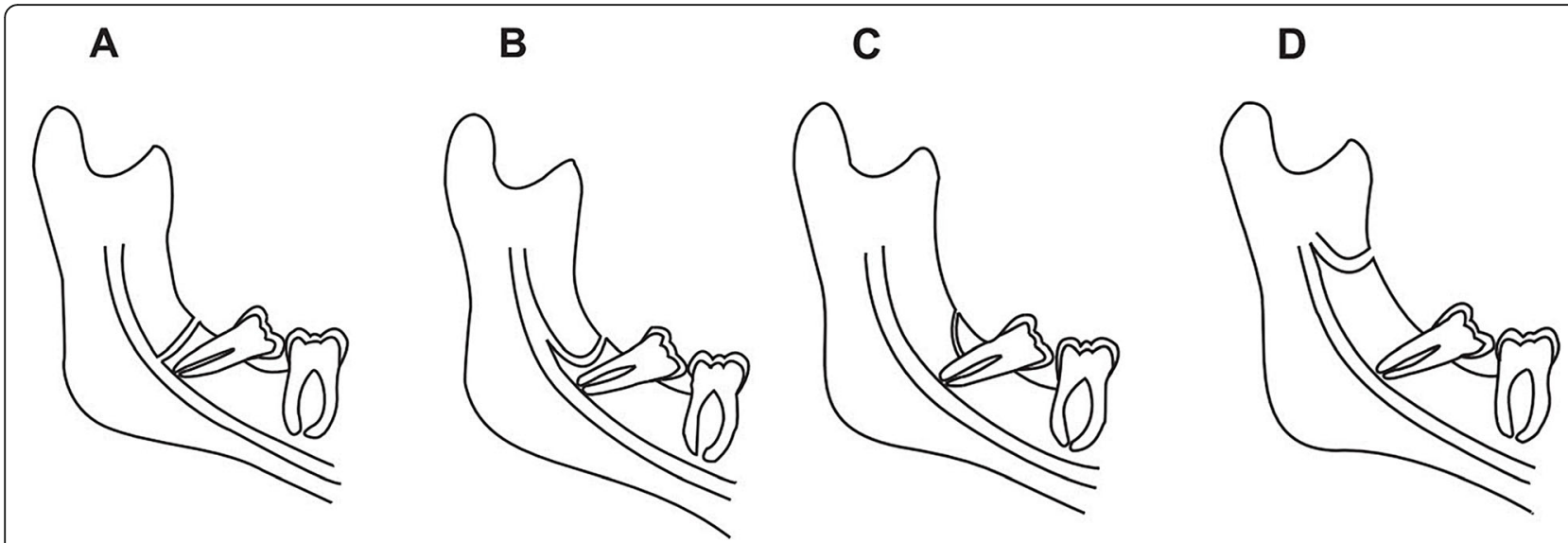

Fig. 4 Classification of RMC. Patil et al.'s schematic illustration of different configurations of the retromolar canal. a Type A1. b Type A2. c Type B. d Type $C$

with Sabban et al. who evaluated the linear measurements at implant sites using the said software [30].

Previous osseous studies of dry mandibles or cadavers were done on different populations investigating the presence of RMF. These studies showed an incidence rate ranging from 3.2 to $72 \%[11,17]$. This wide range may be attributed to the lack of $3 \mathrm{D}$ visualization of the canal system. These studies were not associated with any RMC classification, as these studies only examined the bony surface without sectioning, and therefore, it can be postulated that some of these foramina were not connected to the RMCs.

It is quite obvious that there is a vast difference between the incidence rate reported in panoramic studies due to the limitation of being a 2D modality and CBCT studies; several studies have reclaimed incidence rates of $3-8 \%[14,23,28]$ and $7.3-75.4 \%[5,27]$ in panoramic and CBCT studies, respectively. $11.2 \%$ was reported in this study which falls in the range of the previously reported studies.

Many studies have been done on the Japanese and Korean populations using $\mathrm{CBCT}$ with incidence rate ranging from 25.4 to $75.4 \%$ [5, 12, 31] and 8.5 to $17.4 \%$ [21, $32,33]$, respectively; this wide range of incidence rate can be explained by many factors like the ethnic, genetic, and environmental factors [11,34].

The wide range of incidence rate of RMC in different studies can be attributed also to the sample size

Table 1 Incidence of RMC according to number of patients

\begin{tabular}{|c|c|c|c|c|c|c|c|c|c|}
\hline & \multicolumn{4}{|l|}{ Sex } & \multirow{2}{*}{\multicolumn{2}{|c|}{ Total }} & \multirow{3}{*}{$\begin{array}{l}x^{2} \\
\text { value }\end{array}$} & \multirow{3}{*}{$\begin{array}{l}x^{2} \\
\text { sig }\end{array}$} & \multirow{3}{*}{$\begin{array}{l}\text { Fisher's } \\
\text { exact } \\
\text { test }\end{array}$} \\
\hline & \multicolumn{2}{|c|}{ Male } & \multicolumn{2}{|c|}{ Female } & & & & & \\
\hline & No. & $\%$ & No. & $\%$ & No. & $\%$ & & & \\
\hline Absence & 91 & 42.5 & 99 & 46.3 & 190 & 88.8 & .336 & .562 & .666 \\
\hline Presence & 13 & 6.1 & 11 & 5.1 & 24 & 11.2 & & & \\
\hline Total & 104 & 48.6 & 110 & 51.4 & 214 & 100.0 & & & \\
\hline
\end{tabular}

difference in each study and the inclusion and exclusion criteria; a study with large sample size 300 CBCT scans which was done on the Brazilian population showed an incidence rate of $5 \%$ only [27], while the study done on 84 CBCT scans only of the Chilean population showed an incidence rate of $23.8 \%$ [35].

Some researchers found a notably higher incidence rate than that found in this current study. For instance, Kawai et al. found a prevalence rate of 52\% among the Japanese population [12]. Patil et al. found a prevalence rate of $75.4 \%$ as well [5]. This may be attributed to the smaller voxel size used in these studies, which was $0.1 \mathrm{~mm}$ and $0.08 \mathrm{~mm}$, respectively. On the other hand, Han and Hwang found an incidence rate of $8.5 \%$ when using a $0.38-\mathrm{mm}$ voxel size [21]. Thus, the voxel size of CBCT scans examined affects the quality of the image; a smaller voxel size allows the visualization of much narrower canals therefore affecting the incidence rate in each study $[5,11,21]$.

Freitas et al. used a voxel size of $0.25 \mathrm{~mm}$ using an iCAT CBCT Scanner in a protocol similar to ours and showed a comparable result of $7.33 \%$ incidence rate in the Brazilian population [27]. Also, a recent study done on the Turkish population showed comparable results $[36,37]$.

Although the number of RMCs found in males was greater than that found in females, there was no significant difference in gender, which agrees with the findings of Patil et al., Sawyer and Kiely, and Pyle et al. [5, 38, 39].

Table 2 Incidence of RMC according to the number of sides

\begin{tabular}{|c|c|c|c|c|c|c|c|c|c|}
\hline & \multicolumn{4}{|l|}{ Sex } & \multirow{2}{*}{\multicolumn{2}{|c|}{ Total }} & \multirow{3}{*}{$\begin{array}{l}x^{2} \\
\text { value }\end{array}$} & \multirow{3}{*}{$\begin{array}{l}x^{2} \\
\text { sig }\end{array}$} & \multirow{3}{*}{$\begin{array}{l}\text { Fisher's } \\
\text { exact } \\
\text { test }\end{array}$} \\
\hline & \multicolumn{2}{|c|}{ Male } & \multicolumn{2}{|c|}{ Female } & & & & & \\
\hline & No. & $\%$ & No. & $\%$ & No. & $\%$ & & & \\
\hline Absence & 191 & 44.6 & 207 & 48.4 & 398 & 93.0 & .841 & .359 & .449 \\
\hline Presence & 17 & 4.0 & 13 & 3.0 & 30 & 7.0 & & & \\
\hline Total & 208 & 48.6 & 220 & 51.4 & 428 & 100.0 & & & \\
\hline
\end{tabular}


Table 3 The distribution of canal type presence in each side

\begin{tabular}{|c|c|c|c|c|c|c|c|c|c|}
\hline \multirow{2}{*}{\multicolumn{2}{|c|}{ Side }} & \multicolumn{5}{|c|}{ Canal types } & \multirow[t]{2}{*}{ Total } & \multirow{2}{*}{$\begin{array}{l}x^{2} \\
\text { value }\end{array}$} & \multirow{2}{*}{$\begin{array}{l}\overline{x^{2}} \\
\text { sig }\end{array}$} \\
\hline & & $\begin{array}{l}\text { Type } \\
\text { A1 }\end{array}$ & $\begin{array}{l}\text { Type } \\
\text { A2 }\end{array}$ & Type A & $\begin{array}{l}\text { Type } \\
\text { B }\end{array}$ & Type C & & & \\
\hline \multirow[t]{2}{*}{ Left } & $N$ & 7 & 6 & 13 & 2 & 1 & 16 & 1.210 & .876 \\
\hline & $\%$ & $1.635 \%$ & $1.401 \%$ & $3.036 \%$ & $0.47 \%$ & $0.234 \%$ & $3.74 \%$ & & \\
\hline \multirow[t]{2}{*}{ Right } & $N$ & 7 & 3 & 10 & 3 & 1 & 14 & & \\
\hline & $\%$ & $1.635 \%$ & $0.7 \%$ & $2.335 \%$ & $0.7 \%$ & $0.23 \%$ & $3.26 \%$ & & \\
\hline \multirow[t]{2}{*}{ Total } & $N$ & 14 & 9 & 23 & 5 & 2 & 30 & & \\
\hline & $\%$ & $3.27 \%$ & $2.1 \%$ & $5.37 \%$ & $1.16 \%$ & $0.47 \%$ & $7.0 \%$ & & \\
\hline
\end{tabular}

The number of unilateral canals was found to be greater than that of the bilateral canals, the majority of which were found in the left side of the mandible. However, there was no significant difference which also agrees with the findings of Patil et al., von Arx et al., and Sagne et al. [5, 14, 40].

In this study, we have adopted Patil et al.'s system for the classification of RMCs [5]. We found it to be the most convenient classification. Ossenberg's [11], Park's [41], and Jamalpour et al.'s [41] classifications did not include the canal type which starts from the RMF and ends in the radicular portion of the 3rd molar.

According to the course of the canals, the most common type in our study was type A (23/30), followed by type $B(5 / 30)$, and type $C$ was the rarest type with only $2 / 30$. These results are different from Patil et al.'s study that found type B to be the most common. This can be explained by the voxel size used in their study $(0.08 \mathrm{~mm})$ which allowed them to investigate much narrower canals, and most of the type B canals in Patil et al.'s study are of very small diameter [5].

Regarding linear measurements, the present study found the distance between the RMF and the distal surface of the second molar to be $14.70 \pm 5.07$, which was comparable to the results of $\mathrm{Han}$ et al. who found the distance to be $14.08 \pm 3.85$, von Arx et al. who found the distance to be $15.16 \pm 2.39 \mathrm{~mm}$, and Park et al. who found the distance to be $12.1 \pm 3.3 \mathrm{~mm}[14,15,21]$. Park et al. and Ogawa et al. found the distance between the RMF and the third molar to be $5.8 \pm 3.6 \mathrm{~mm}$ and $5.5 \pm$ 2.1, respectively, which are not much different from our

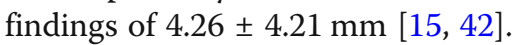

Table 4 Incidence of RMC in each side

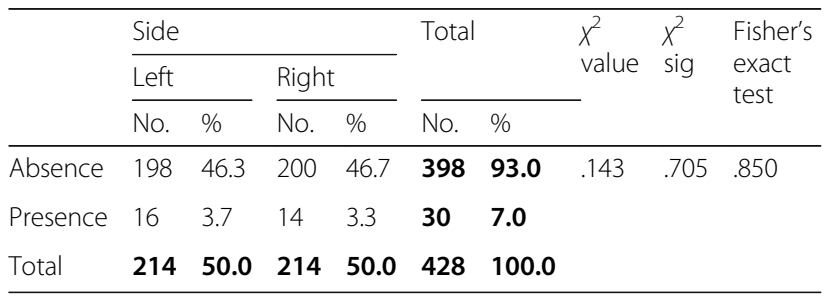

Table 5 Description of the different linear measurements of retromolar canals

\begin{tabular}{ll}
\hline Category & Total \\
\hline A-P from RMF to MF & $15.69 \pm 3.43(8.26-22.94)$ \\
M-L from RMF to MF & $2.62 \pm 1.60(.38-6.80)$ \\
A-P from RMF to 3rd molar & $4.26 \pm 4.21(.00-12.09)$ \\
A-P from RMF to 2nd molar & $14.70 \pm 5.07(.00-23.70)$ \\
\hline
\end{tabular}

This study has the merits of being the first study done to investigate the RMC and RMF in the Egyptian population and highlight the incidence rate and the importance of knowing such abnormality; also, these measurements may aid the clinician to better localize the RMF in various clinical procedures. Thus, the 2nd and 3rd molars can be used as anatomical landmarks, hence saving the surgeon from the complication of damaging the retromolar nerve and its associated morbidity.

This study has the limitation of using a relatively large voxel size $0.25 \mathrm{~mm}$ which did not allow us to observe and investigate canals narrower than $0.5 \mathrm{~mm}$; also, all data was collected from the Faculty of Dentistry of Ain Shams University located in Cairo governate and so the DICOM data investigated may not represent the whole Egyptian population.

\section{Conclusion}

The incidence rate of the RMC in the Egyptian population represents $11.2 \%$.

The use of CBCT is quite important in the evaluation of the retromolar area to visualize the presence of the RMC or RMF and avoid the complications occurring due to different dental surgical procedures performed in the aforementioned site.

\section{Abbreviations}

2D: Two-dimensional; 3D: Three-dimensional; CBCT: Cone beam computed tomography; DICOM: Digital Imaging and Communications in Medicine; FOV: Field of view; IAC: Inferior alveolar canal; IAN: Inferior alveolar nerve; MF: Mandibular foramen; MPR: Multi-planner reconstruction; MSCT: Multislice computed tomography; RMC: Retromolar canal; RMF: Retromolar foramen; SPSS: Statistical Package for Social Science

\section{Acknowledgements}

Not applicable.

\section{Authors' contributions}

MS examined all the CBCT scans, recorded the presence of the RMC or RMF, and did the linear measurements. FM performed the second examination of the CBCT scans and wrote the primary manuscript. WM was the major contributor in writing and editing the manuscript. All authors read and approved the final manuscript.

\section{Funding}

Not applicable.

\section{Availability of data and materials}

The following link contains the screenshots of cases, the excel sheet used to record and document all the data and measurements, and the statistical 
results PDF file: https://drive.google.com/open?id=1FbQIJXA5Ste-5W71 JAjsNQbMJj590HwK.

\section{Ethics approval and consent to participate}

This study was approved by the ethics committee of the Faculty of Dentistry, Ain Shams University. Reference number: FDASU-REC EM 022023.

\section{Consent for publication}

The data used in this study was collected from the Radiology Department of the Faculty of Dentistry, Ain Shams University, after the approval of the ethics committee, and all data was anonymized and only the gender and the date of birth of the case were known. All patients included in this research gave written informed consent to publish the data contained within this study. If the patient was less than 16 years old, deceased, or unconscious when consent for publication was requested, written informed consent for the publication of this data was given by their parents or legal guardian.

\section{Competing interests}

The authors declare that they have no competing interests.

\section{Author details}

'The British University in Egypt, Cairo, Egypt. ${ }^{2}$ Faculty of Dentistry, Ain Shams University, Cairo, Egypt.

Received: 5 February 2020 Accepted: 17 March 2020

Published online: 23 March 2020

\section{References}

1. Kuribayashi A, Watanabe H, Imaizumi A, Tantanapornkul W, Katakami K, Kurabayashi T (2010) (2010). Bifid mandibular canals: cone beam computed tomography eva luation. Dentomaxillofacial Radiol 39:235-239 https://doi. org/10.1259/dmfr/66254780

2. Torres MGG, de Valverde LF, Andion Vidal MT, Crusoé-Rebello IM (2015) Accessory mental foramen: a rare anatomical variation detected by conebeam computed tomography. Imaging Sci Dent 45:61-65 https://doi.org/ 10.5624/isd.2015.45.1.61

3. Zmysłowska-Polakowska E, Radwański M, Łęski M, Ledzion S, ŁukomskaSzymańska M, Polguj M (2017) The assessment of accessory mental foramen in a selected Polish population: a CBCT study. BMC Med Imaging 2017:17 https://doi.org/10.1186/s12880-017-0188-6

4. Sheikhi M, Mosavat F, Ahmadi A (2012) Assessing the anatomical variations of lingual foramen and its bony canals with CBCT taken from 102 patients in Isfahan. Dent Res J (Isfahan) 9:S45-S51

5. Patil S, Matsuda Y, Nakajima K, Araki K, Okano T (2013) Retromolar canals as observed on cone-beam computed tomography: their incidence, course, and characteristics. Oral Surg Oral Med Oral Pathol Oral Radiol 115:692-699 https://doi.org/10.1016/j.000o.2013.02.012

6. Starkie C, Stewart D (1931) The intra-mandibular course of the inferior dental nerve. J Anat 65:319-323

7. Loizeaux AD, Devos BJ (1981) Inferior alveolar nerve anomaly. J Hawaii Dent Assoc 12:10-11

8. Kodera H, Hashimoto I (1995) A case of mandibular retromolar canal: elements of nerves and arteries in this canal. Kaibogaku Zasshi 70:23-30

9. Jablonski NG, Cheng CM, Cheng LC, Cheung HM (1985) Unusual origins of the buccal and mylohyoid nerves. Oral Surgery. Oral Med Oral Pathol 60: 487-488 https://doi.org/10.1016/0030-4220(85)90235-X

10. Singh S (1981) Aberrant buccal nerve encountered at third molar surgery. Oral Surgery, Oral Med Oral Pathol 52:142 https://doi.org/10.1016/00304220(81)90310-8

11. Ossenberg NS (1987) Retromolar foramen of the human mandible. Am J Phys Anthropol 73:119-128 https://doi.org/10.1002/ajpa.1330730112

12. Kawai T, Asaumi R, Sato I, Kumazawa Y, Yosue T (2012) Observation of the retromolar foramen and canal of the mandible: a CBCT and macroscopic study. Oral Radiol 28:10-14 https://doi.org/10.1007/s11282-011-0074-9

13. Cennet $\mathrm{E}$, Levent $\mathrm{C}$ (2015) Case report: aberrant buccal nerve in the retromolar canal. Indian J Basic Appl Med Res 4:239-241

14. Von Arx T, Hänni A, Sendi P, Buser D, Bornstein MM (2011) Radiographic study of the mandibular retromolar canal: an anatomic structure with clinical importance. J Endod 37:1630-1635 https://doi.org/10.1016/j.joen. 2011.09.007

15. Park MK, Jung W, Bae JH, Kwak HH (2016) Anatomical and radiographic study of the mandibular retromolar canal. J Dent Sci 11:370-376 https://doi. org/10.1016/j.jds.2016.04.002

16. Bilecenoglu B, Tuncer $N$ (2006) Clinical and anatomical study of retromolar foramen and canal. J Oral Maxillofac Surg 64:1493-1497 https://doi.org/10. 1016/j.joms.2006.05.043

17. Schejtman $\mathrm{R}$, Devoto $\mathrm{FCH}$, Arias NH. The origin and distribution of the elements of the human mandibular retromolar canal. Arch Oral Biol 1967;12: 1261-1267. https://doi.org/10.1016/0003-9969(67)90127-6.

18. Nortj CJ, Farman AG, Grotepass FW (1977) Variations in the normal anatomy of the inferior dental (mandibular) canal: a retrospective study of panoramic radiographs from 3612 routine dental patients. Br J Oral Surg 15:55-63

19. Scarfe WC, Farman AG (2006) Clinical applications of cone-beam computed. J Can Dent Assoc 72:75-80

20. Scarfe WC, Farman AG (2008) What is cone-beam ct and how does it work? Dent Clin North Am 52:707-730 https://doi.org/10.1016/j.cden.2008.05.005

21. Han SS, Hwang YS (2014) Cone beam CT findings of retromolar canals in a Korean population. Surg Radiol Anat 36:871-876 https://doi.org/10.1007/ s00276-014-1262-1

22. Alves N, Deana NF (2015) Anatomical and radiographical study of the retromolar canal and retromolar foramen in macerated mandibles. Int J Clin Exp Med 8:4292-4296

23. de O Capote TS, de A Gonçalves M, Campos JÁDB (2015) Retromolar canal associated with age, side, sex, bifid mandibular canal, and accessory mental foramen in panoramic radiographs of Brazilians. Anat Res Int 2015:1-8 https://doi.org/10.1155/2015/434083

24. Potu BK, Kumar V, Salem A-H, Abu-Hijleh M (2014) Occurrence of the retromolar foramen in dry mandibles of south-eastern part of India: a morphological study with review of the literature. Anat Res Int 2014:1-5 https://doi.org/10.1155/2014/296717

25. Tiwari S, Ramakrishna R, Sangeeta M (2015) A study on the incidence of retromolar foramen in South Indian adult dried human mandibles and its clinical relevance. Int J Res Med Sci 3:1383-1387 https://doi.org/10.18203/ 2320-6012.ijrms20150152

26. Potu BK, Salem AH, Raouf HA, Kader GA, Hijleh MA (2015) Occurrence of the retromolar foramen in Egyptian dry mandibles: a preliminary morphological study. Oral Surg Oral Med Oral Pathol Oral Radiol 119:e200-e201 https://doi. org/10.1016/j.0000.2014.07.437

27. Freitas GB de, Freitas E Silva A de, Manhães Júnior LRC. The prevalence of mandibular retromolar canals on cone beam computed tomography and its clinical repercussions. Rev Odontol Da UNESP 2017;46:158-163. https:// doi.org/10.1590/1807-2577.00117

28. Sisman Y, Ercan-Sekerci A, Payveren-Arıkan M, Sahman H (2015) Diagnostic accuracy of cone-beam CT compared with panoramic images in predicting retromolar canal during extraction of impacted mandibular third molars. Med Oral Patol Oral Cir Bucal 20:e74-e81 https://doi.org/10.4317/medoral. 19930

29. Truong MK, He P, Adeeb N, Oskouian RJ, Tubbs RS, Iwanaga J (2017) Clinical anatomy and significance of the retromolar foramina and their canals: a literature review. Cureus 9(10):e1781 https://doi.org/10.7759/cureus.1781

30. Sabban H, Mahdian M, Dhingra A, Lurie AG, Tadinada A (2015) Evaluation of linear measurements of implant sites based on head orientation during acquisition: an ex vivo study using cone-beam computed tomography. Imaging Sci Dent 45:73-80 https://doi.org/10.5624/isd.2015.45.2.73

31. Naitoh M, Hiraiwa $Y$, Aimiya $H$, Ariji E (2008) Observation of bifid mandibular canal using conebeam computed tomography. Int J Oral Maxillofac Implants 24:155-159

32. Rashsuren O, Choi J-W, Han W-J, Kim E-K (2014) Assessment of bifid and trifid mandibular canals using cone-beam computed tomography. Imaging Sci Dent 44:229-236 https://doi.org/10.1259/dmfr/60245722

33. Kang JH, Lee KS, Oh MG, Choi HY, Lee SR, Oh SH (2014) The incidence and configuration of the bifid mandibular canal in Koreans by using cone-beam computed tomography. Imaging Sci Dent 44:53-60 https://doi.org/10.5624/ isd.2014.44.1.53

34. Haas LF, Dutra K, Porporatti AL, Mezzomo LA, De Luca CG, Flores-Mir C (2015) Anatomical variations of mandibular canal detected by panoramic radiography and $\mathrm{CT}$ : a systematic review and meta-analysis. Dentomaxillofacial Radiol 45:1-12 https://doi.org/10.1259/dmfr.20150310 
35. López-Videla Montaño J, Vergara Miranda M, Rudolph Rojas M, Guzmán Zuluaga CL (2010) Prevalencia de variables anatómicas en el recorrido de los conductos mandibulares: Estudio mediante tecnología Cone Beam. Rev Fac Odontol Univ Antioquia 22:23-32

36. LAÇIN N, TATAR B, VELI İ, AYTUĞAR E (2019) Evaluation of the retromolar canal and foramina of the mandible with cone-beam computed tomography. J Harran Univ Med Fac 16:139-142

37. Ahuja SB, Bhardwaj NS, Dang V, Ahuja R, Mathur H (2018) Prevalence of retromolar canal and foramen: a cone beam computed tomography study. J Indian Acad Oral Med Radiol 30:8-11 https://doi.org/10.4103/jiaomr.jiaomr

38. Sawyer DR, Kiely ML (1991) Retromolar foramen: a mandibular variant important to dentistry. Ann Dent 50:16-18

39. Pyle MA, Jasinevicius TR, Lalumandier JA, Kohrs KJ, Sawyer DR (1999) Prevalence and implications of accessory retromolar foramina in clinical dentistry. Gen Dent 47:500-503 quiz 504-5

40. Sagne S, Olsson G, Hollender $L$ (1977) Retromolar foramina and canals in the human mandible. Dentomaxillofacial Radiol 6:41-45 https://doi.org/10, 1259/dmfr.1977.0005

41. Jamalpour M, Shokri A, Falah-koshki S, Zavareian A (2016) Evaluation of retromolar canals with cone beam-computed tomography in an Iranian adult population: a retrospective study. Int J Clin Dent 9:59-66

42. Ogawa A, Fukuta Y, Nakasato H, Nakasato S (2016) Evaluation by dental cone-beam computed tomography of the incidence and sites of branches of the inferior dental canal that supply mandibular third molars. Br J Oral Maxillofac Surg 54:1116-1120 https://doi.org/10.1016/j.bjoms.2016.08.007

\section{Publisher's Note}

Springer Nature remains neutral with regard to jurisdictional claims in published maps and institutional affiliations.

\section{Submit your manuscript to a SpringerOpen ${ }^{\circ}$ journal and benefit from:}

- Convenient online submission

- Rigorous peer review

- Open access: articles freely available online

- High visibility within the field

- Retaining the copyright to your article

Submit your next manuscript at $\boldsymbol{\nabla}$ springeropen.com 